\title{
Papers
}

\section{Modification of cystatin C activity by bacterial proteinases and neutrophil elastase in periodontitis}

\author{
Magnus Abrahamson, Maude Wikström, Jan Potempa, Stefan Renvert, Anders Hall
}

Department of Clinical Chemistry, University of Lund, University Hospital, S-221 85 Lund, Sweden M Abrahamson A Hall

Department of Oral Microbiology,

University of

Göteborg, S-413 46

Göteborg, Sweden

$\mathrm{M}$ Wikström

Department of Microbiology and Immunology, Institute of Molecular Biology, Jagiellonian University, Kraków, Poland; and Department of

Biochemistry,

University of Georgia, Athens, Georgia 30602, USA

J Potempa

Department of Periodontology, Public Dental Service, S-291 33 Kristianstad, Sweden

S Renvert

Correspondence to:

Dr Abrahamson.

Accepted for publication 9 October 1997
Abstract human cysteine proteinase inhibitor, cystatin $\mathbf{C}$, and proteinases of periodontitis associated bacteria.

Methods-Gingival crevicular fluid samples were collected from discrete periodontitis sites and their cystatin $C$ content was estimated by enzyme linked immunosorbent assay (ELISA). The interaction between cystatin $C$ and proteolytic enzymes from cultured strains of the gingival bacteria Porphyromonas gingivalis, Prevotella intermedia, and Actinobacillus actinomycetemcomitans was studied by measuring inhibition of enzyme activity against peptidyl substrates, by detection of break down patterns of solid phase coupled and soluble cystatin $C$, and by $\mathbf{N}$-terminal sequence analysis of cystatin $C$ products resulting from the interactions.

Results-Gingival crevicular fluid contained cystatin $C$ at a concentration of $\sim 15$ nM. Cystatin $C$ did not inhibit the principal thiol stimulated proteinase activity of $P$ gingivalis. Instead, strains of $P$ gingivalis and $P$ intermedia, but not $A$ actinomycetemcomitans, released cystatin $\mathbf{C}$ modifying proteinases. Extracts of five $P$ gingivalis and five $P$ intermedia strains all hydrolysed bonds in the $\mathrm{N}$-terminal region of cystatin $\mathbf{C}$ at physiological pH values. The modified cystatin $C$ resulting from incubation with one $P$ gingivalis strain was isolated and found to lack the eight most $\mathbf{N}$-terminal residues. The affinity of the modified inhibitor for cathepsin $B$ was 20-fold lower $\left(K_{1} 5\right.$ nM) than that of full length cystatin C. A $50 \mathrm{kDa}$ thiol stimulated proteinase, gingipain $R$, was isolated from $P$ gingivalis and shown to be responsible for the Arg8bond hydrolysis in cystatin $C$. The cathep$\sin B$ inhibitory activity of cystatin $C$ incubated with gingival crevicular fluid was rapidly abolished after Val10- bond cleavage by elastase from exudate neu- trophils, but cleavage at the gingipain specific Arg8-bond was also demonstrated. Conclusions-The physiological control of cathepsin $B$ activity is impeded in periodontitis, owing to the release of proteinases from infecting $P$ gingivalis and neutrophils, with a contribution to the tissue destruction seen in periodontitis as a probable consequence.

(F Clin Pathol: Mol Pathol 1997;50:291-297)

Keywords: cysteine proteinase inhibitor; Porphyromonas gingivalis; Prevotella intermedia; Actinobacillus actinomycetemcomitans; cathepsin $\mathrm{B}$; periodontitis

Human cystatin $C$, a single chain protein of 120 amino acid residues, ${ }^{12}$ is a potent inhibitor of papain-like cysteine proteinases such as the human lysosomal enzymes cathepsins $\mathrm{B}, \mathrm{H}, \mathrm{L}$, and $\mathrm{S}^{3{ }^{34}}$ It interacts reversibly with these proteinases and binds in their active site clefts in competition with substrate. The $\mathrm{N}$-terminal segment of the inhibitor constitutes a discrete enzyme binding region, which is an important contributor to the high affinity inhibition of human cysteine proteinases through interactions with their substrate binding pockets. ${ }^{5-8}$ Another, wedge shaped enzyme binding region that constitutes the remainder of the target proteinase contact area is built from residues in two hairpin loops corresponding to the central Gln-55-Gly-59 segment and a segment towards the C-terminal part of the inhibitor chain. $^{910}$

Cystatin $\mathrm{C}$ is synthesised in most tissues of the body and has been found in all major biological fluids, which is a uniquely wide distribution for the low $M_{r}$ cysteine proteinase inhibitors belonging to family 2 of the cystatin superfamily. ${ }^{11}$ Moreover, extracellular concentrations of cystatin $\mathrm{C}$ are sufficiently high to allow efficient control of the activities of cathepsin $\mathrm{B}, \mathrm{H}$, or $\mathrm{L}$ if released into any of the major body fluids. ${ }^{611}$ Cathepsin B and/or L have been detected extracellularly in conditions like endotoxin induced sepsis, ${ }^{12}$ metastasising cancer, ${ }^{13}$ and at the sites of local inflammatory processes in rheumatoid arthritis, ${ }^{14}$ purulent bronchiectasis, ${ }^{15}$ and periodontitis. ${ }^{16}$ The especially high concentrations of cystatin $C$ and 
other family 2 cystatins in secretions like saliva, tears, and seminal plasma indicate that the inhibitors might have an additional function in the defence against invading microorganisms. However, the few characterised cysteine proteinases of disease causing bacteria do not seem to belong to the superfamily of papain-like enzymes. For example, the cysteine proteinase of group A streptococci (and growth of the bacteria) can be inhibited by synthetic cystatin $\mathrm{C}$ based peptidyl diazomethylketone inhibitors but not by cystatin C itself. ${ }^{17}$ Similarly, a cysteine proteinase of Staphylococcus aureus is not inhibited by cystatin C. ${ }^{18}$ Other examples of bacterial cysteine proteinases include clostripain from Clostridium histolyticum ${ }^{19}$ and a secreted enzyme from Porphyromonas gingivalis.

$P$ gingivalis, Prevotella intermedia, and Actinobacillus actinomycetemcomitan seem to be the principal pathogens responsible for the destruction of the tooth supporting tissue, known as periodontitis. ${ }^{20}$ Among the numerous putative virulence factors of these periodontopathogenic bacteria, the primary focus of research has been on proteolytic enzymes elaborated in large quantities by $P$ gingivalis. Such enzymes catalyse degradation of extracellular matrix and iron binding proteins, immunoglobulins, factors of the complement and coagulation cascades, bactericidal proteins and peptides, and iron transporting/sequestering proteins. Their action also results in inactivation of host serine proteinase inhibitors and activation of host matrix metalloproteinases as well as the kallikrein/kinin cascade. ${ }^{21}$ In addition to providing essential nutrients for the subgingival bacteria, the $P$ gingivalis enzymes are thus implicated in the processes of evasion of host defence mechanisms and penetration/ destruction of connective tissue. For a considerable amount of time the major proteolytic activity of $P$ gingivalis was classified as a thiol dependent trypsin-like activity, although other types of enzyme activities such as that of a collagenase $^{22}$ and a serine proteinas $\mathrm{e}^{23}$ have also been noticed. Attempts to purify and characterise the trypsin-like proteinase yielded a considerable amount of ambiguous data, creating a confusing picture of $P$ gingivalis as a bacterium producing a myriad of related but nonidentical proteinases. Fortunately, recent rigorous purification of $P$ gingivalis cysteine proteinases $^{24}{ }^{25}$ and elucidation of their structures at the gene and protein levels, ${ }^{26}$ backed up by western blot analysis combined with zymography and inhibition studies, ${ }^{27}$ revealed that in most $P$ gingivalis strains there are only two primary enzymes, one with Arg-Xaa specificity (gingipain R) and the other with Lys-Xaa specificity (gingipain $\mathrm{K}$ ), both of which occur in many different molecular mass forms.

The purpose of the present investigation was to study the interaction between cystatin $\mathrm{C}$ and proteinases of periodontitis associated bacteria, especially with respect to possible inhibition of the thiol stimulated Arg-Xaa specific enzyme activity of $P$ gingivalis. We show that the principal $P$ gingivalis cysteine proteinase is not inhibited by the cystatin but that, instead, both $P$ gingivalis and $P$ intermedia have the capacity to modify the inhibitor proteolytically, with a consequent negative effect on the inhibitory properties of cystatin C.

\section{Materials and methods}

MATERIALS

Human cystatin C was produced by Escherichia coli expression, and purified as described earlier. ${ }^{28}$ Human cathepsin B (EC 3.4.22.1), affinity purified by the procedure of Rich $e t a l,{ }^{29}$ was purchased from Calbiochem (La Jolla, California, USA). Papain (EC 3.4.22.2) was isolated from commercial papain (Sigma, St Louis, Missouri, USA; type III) by affinity chromatography according to the protocol described by Blumberg et al, ${ }^{30}$ but using the peptide H-Gly-Gly-Tyr-Arg-OH coupled to $\mathrm{CNBr}$ activated Sepharose 4B (Pharmacia, Uppsala, Sweden). The enzyme substrates Cbz-Phe-Arg-NHMec and Bz-DL-Arg-pNA were obtained from Bachem Feinchemikalien (Bubendorf, Switzerland) and the synthetic inhibitor tosyl-Lys-chloromethyl ketone came from Sigma. All chemicals used were of analytical grade and were obtained from Sigma.

\section{PROTEIN ANALYSES}

Analytical agarose gel electrophoresis in barbital buffer, $\mathrm{pH} 8.6$, was performed according to Jeppsson et al. ${ }^{31}$ Polyacrylamide gel slab electrophoresis in the presence of sodium dodecyl sulphate (SDS-PAGE) was performed as described by Laemmli, ${ }^{32}$ with separation gels containing $20 \%$ acrylamide or in gradients of 8-20\% acrylamide. Automated N-terminal sequence analysis with an Applied Biosystems $470 \mathrm{~A}$ sequencer was performed by standard methods, after blotting of electrophoretically separated protein bands from agarose or polyacrylamide gels to poly(vinyldifluoride) membranes (Trans-blot; Bio-Rad, Hercules, California, USA) as described previously. ${ }^{334}$ Concentrations of native recombinant cystatin $\mathrm{C}$ in solutions were determined by $\mathrm{A}_{280}$ measurements $\left(\varepsilon_{280}=12200 / \mathrm{M} / 1\right) .^{35}$

CYSTATIN C DETERMINATION IN GINGIVAL

CREVICULAR FLUID SAMPLES

Gingival crevicular fluid (GCF) from sites with severe periodontitis, with a tooth pocket depth of $>6 \mathrm{~mm}$, was collected from 11 patients by use of paper points as described previously. ${ }^{36}$ Each point was kept in place for 15 seconds and then transferred to a vial containing $100 \mu \mathrm{l}$ of $150 \mathrm{mM} \mathrm{NaCl}$ and kept at $-80^{\circ} \mathrm{C}$ until assayed. Cystatin $\mathrm{C}$ concentrations in the samples were measured with a double sandwich enzyme linked immunosorbent assay (ELISA), ${ }^{37}$ using isolated recombinant human cystatin $\mathrm{C}$ as standard.

BACTERIAL STRAINS

Five $P$ gingivalis strains (OMGS 100, OMGS 478, OMGS 588, OMGS 590, and OMGS 656) and five $P$ intermedia strains (OMGS 53, OMGS 58, OMGS 64, OMGS 104, and OMGS 105), isolated from the subgingival plaque of patients with 
periodontitis, were cultivated on brucella agar plates for three to five days at $36^{\circ} \mathrm{C}$. The cells were washed once in $10 \mathrm{mM}$ phosphate buffer, pH 7.2, containing $150 \mathrm{mM} \mathrm{NaCl}$, pelleted by centrifugation and lyophilised. Crude extracts were prepared by suspending the lyophilised bacteria in $50 \mathrm{mM}$ sodium acetate buffer, $\mathrm{pH} 4.5$, containing $150 \mathrm{mM} \mathrm{NaCl}$ and $5 \mathrm{mM}$ $\mathrm{CaCl}_{2}$, followed by crushing (French press, three times), and centrifugation at $100000 \times g$ for two hours. The supernatant was collected and lyophilised for storage of the extracts. $P$ gingivalis strain OMGS 100, $P$ intermedia strain OMGS 58 and $A$ actinomycetemcomintans strain OMGS 191 were used in protein degrading activity plate assays. $P$ gingivalis strain $\mathrm{H}_{66}{ }^{24}$ was grown in $30 \mathrm{~g} / 1$ Trypticase soy broth (Difco, Detroit, Michigan, USA), $5 \mathrm{~g} / 1$ yeast extract, $5 \mathrm{mg} / 1 \mathrm{hemin}, 0.5 \mathrm{~g} / 1$ cysteine, $0.1 \mathrm{~g} / 1$ dithiothreitol, and $1 \mathrm{mg} / 1$ menadione (all from Sigma) at $37^{\circ} \mathrm{C}$ for 48 hours.

\section{ASSAY OF RELEASED PROTEIN DEGRADING} ACTIVITY FROM CULTURED BACTERIA

The bacteria included in the study were tested for release of cystatin $C$ degrading enzymes by use of a plate screening technique. ${ }^{38}$ The inner surface of a polystyrene Petri dish was coated with recombinant cystatin $C$ from a $10 \mathrm{mg} / \mathrm{ml}$ solution in distilled water, by incubation at room temperature for six hours, and then covered with agar containing cultivation medium. The medium used was brucella agar (BBL Microbiology Systems, Cockeysville, Maryland, USA) with $50 \mathrm{ml} / 1$ defibrinated horse blood, $20 \mathrm{ml} / 1$ haemolysed blood, and $0.5 \mathrm{mg} / 1$ menadione. The bacteria were inoculated as spots on the agar surface and the dishes were incubated at $36^{\circ} \mathrm{C}$ in $95 \% \mathrm{H}_{2}$ and $5 \% \mathrm{CO}_{2}$. The agar was removed after a heavy growth was obtained and the cystatin C coated surface was exposed to water vapour. Degraded cystatin C was seen as a surface with lowered wettability compared with that of the native inhibitor.

\section{PURIFICATION OF GINGIPAIN R}

The $50 \mathrm{kDa}$ Arg-Xaa specific proteinase known as gingipain $\mathrm{R}$ (EC 3.4.22.37) was purified from $P$ gingivalis strain $\mathrm{H} 66$ culture fluid using a combination of acetone precipitation, gel filtration, arginine-Sepharose affinity chromatography and anion exchange chromatography. ${ }^{24}$ The final gingipain $R$ preparation was dialysed against $20 \mathrm{mM}$ bisTris buffer, $\mathrm{pH} 6.8$, containing $150 \mathrm{mM} \mathrm{NaCl}$, $5 \mathrm{mM} \mathrm{CaCl}_{2}$, and $0.02 \%$ (wt/vol) $\mathrm{NaN}_{3}$. The amount of active enzyme was determined by active site titration using D-Phe-Pro-Arg$\mathrm{CH}_{2} \mathrm{Cl}$.

IN VITRO INTERACTIONS BETWEEN BACTERIAL ENZYMES OR GCF AND CYSTATIN C

The interaction of recombinant cystatin $\mathrm{C}$ with proteinases in $P$ gingivalis or $P$ intermedia extracts or culture media was studied in $50 \mathrm{mM}$ Tris- $\mathrm{HCl}$ buffer, $\mathrm{pH} \mathrm{7.4,} \mathrm{containing}$ $150 \mathrm{mM} \mathrm{NaCl}$, or with the same buffer supplemented with $10 \mathrm{mM}$ cysteine. In studies of the cystatin interaction with isolated gingipain R or GCF samples the buffer was supple- mented further with $5 \mathrm{mM} \mathrm{CaCl}$ and $50 \mathrm{mM}$ Gly-Gly. Incubations at $37^{\circ} \mathrm{C}$ were performed in sterile capped microcentrifuge tubes, and samples were taken at timed intervals. Following incubation, proteinase activity was stopped by instant freezing, or by the addition of tosylLys-chloromethyl ketone to a final concentration of $1 \mathrm{mM}$. The degree of cystatin modification was studied by agarose and SDSpolyacrylamide gel electrophoreses. Resulting modified cystatin $\mathrm{C}$ species were analysed by $\mathrm{N}$-terminal sequencing.

ISOLATION AND CHARACTERISATION OF $P$ GINGIVALIS MODIFIED CYSTATIN C

A $2 \mathrm{mg}$ sample of cystatin C was incubated with $3 \mathrm{mg}$ of lyophilised $P$ gingivalis strain

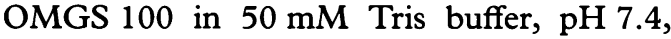
containing $150 \mathrm{mM} \mathrm{NaCl}$ and $10 \mathrm{mM}$ cysteine, for two hours at $37^{\circ} \mathrm{C}$, after which all of the native cystatin $\mathrm{C}$ was modified and displayed altered agarose gel mobility. The modified cystatin $\mathrm{C}$ was isolated by preparative agarose gel electrophoresis ${ }^{39}$ and desalted by gel chromatography at $22^{\circ} \mathrm{C}$ using a Superose $1210 / 30$ column (Pharmacia) in $50 \mathrm{mM}$ ammonium bicarbonate, $\mathrm{pH} 8.0$, with a flow rate of $18 \mathrm{ml} /$ hour. $M_{r}$ estimation of the modified cystatin was performed by SDS-PAGE in the presence or absence of $\beta$-mercaptoethanol, and by gel chromatography using the Superose column as described above with bovine serum albumin $\left(M_{r}, 67000\right)$, ovalbumin $\left(M_{r}\right.$, $43000)$, $\beta$-lactoglobulin ( $\left.M_{r}, 35000\right)$, human carbonic anhydrase $B\left(M_{r}, 28700\right)$, chymotrypsinogen $\left(M_{r}, 23250\right)$, bovine ribonuclease $\left(M_{r}, 12650\right)$, cytochrome $C\left(M_{r}, 12400\right)$ and aprotinin $\left(M_{r}, 6500\right)$ as calibrators.

\section{ENZYME ASSAYS}

Concentrations of inhibitory active cystatin in samples for kinetic studies were determined by titration of affinity purified papain, which itself had been titrated with E-64 $4^{40}$ as described. ${ }^{41}$ The same assay based on hydrolysis of Bz-DLArg-pNA was used to measure the trypsin-like cysteine proteinase activity of $P$ gingivalis extracts or media. For determination of equilibrium constants for dissociation $\left(\mathrm{K}_{\mathrm{i}}\right)$ of complexes between full length or proteolytically modified cystatin $\mathrm{C}$ and human cathepsin $\mathrm{B}$, continuous rate assays with $\mathrm{Cbz}-\mathrm{Phe}-\mathrm{Arg}$ NHMec as substrate at $\mathrm{pH} 6.0$ were used, and the results were evaluated as described in detail elsewhere. ${ }^{8}$

\section{Results}

PRESENCE OF CYSTATIN C IN GINGIVAL CREVICULAR FLUID

GCF samples were collected from 11 patients with untreated severe periodontitis by paper points that were subsequently eluted in $100 \mu \mathrm{l}$ $\mathrm{NaCl}$ solution. Because the GCF volume normally absorbed by the method is around $5 \mu \mathrm{l},{ }^{36}$ the resulting samples represented approximately 20-fold dilutions of GCF. Immunochemical quantitation of cystatin $C$ in the samples revealed that all contained cystatin C (range, 2.2-39 ng/ml). The mean cystatin C concentration in the original GCF, taking the 


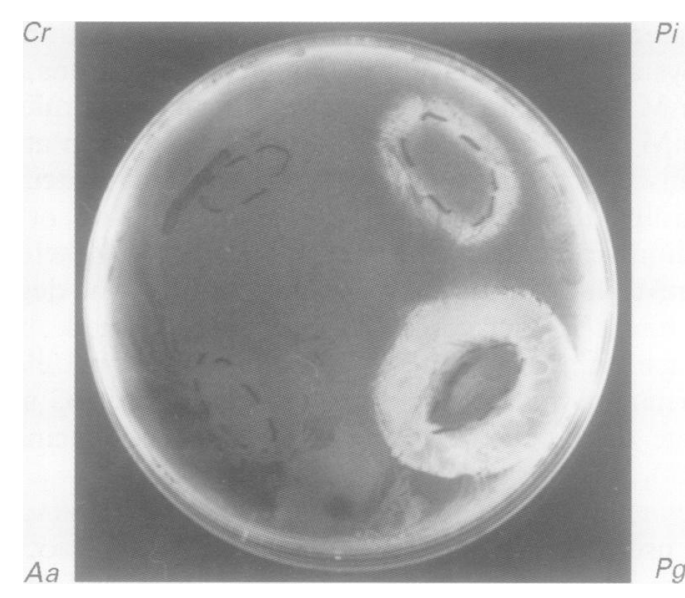

Figure 1 Release of cystatin $C$ degrading proteinases from periodontopathic bacteria. The inner surface of a polystyrene Petri dish was coated with recombinant cystatin $C$ and then covered with agar containing cultivation medium. Bacterial specimens were seeded on to the agar and allowed to grow until large colonies were obtained. The agar was then removed and the cystatin $C$ coated surface was exposed to water vapour to visualise zones of degraded protein. Cr, Campylobacter rectus (negative control); $A a$, Actinobacillus actinomycetemcomitans; Pi, Prevotella intermedia; $\mathrm{Pg}$, Porphyromonas gingivalis.

dilution into account, was $\sim 0.2 \mu \mathrm{g} / \mathrm{ml}$ or $15 \mathrm{nM}$.

\section{INTERACTION BETWEEN CYSTATIN C AND} PROTEINASES FROM PERIODONTITIS ASSOCIATED BACTERIA

To investigate the possibility that cystatin $\mathrm{C}$ inhibited the trypsin-like cysteine proteinase activity of $P$ gingivalis, a bacterial extract was assayed with Bz-Arg-pNA as substrate. When added to this assay, cystatin $\mathrm{C}$ did not result in complete inhibition of the enzyme activity, even at concentrations of up to $7.5 \mathrm{mM}$. However, a low degree of inhibitory activity was apparent, resembling that of a competing sub-

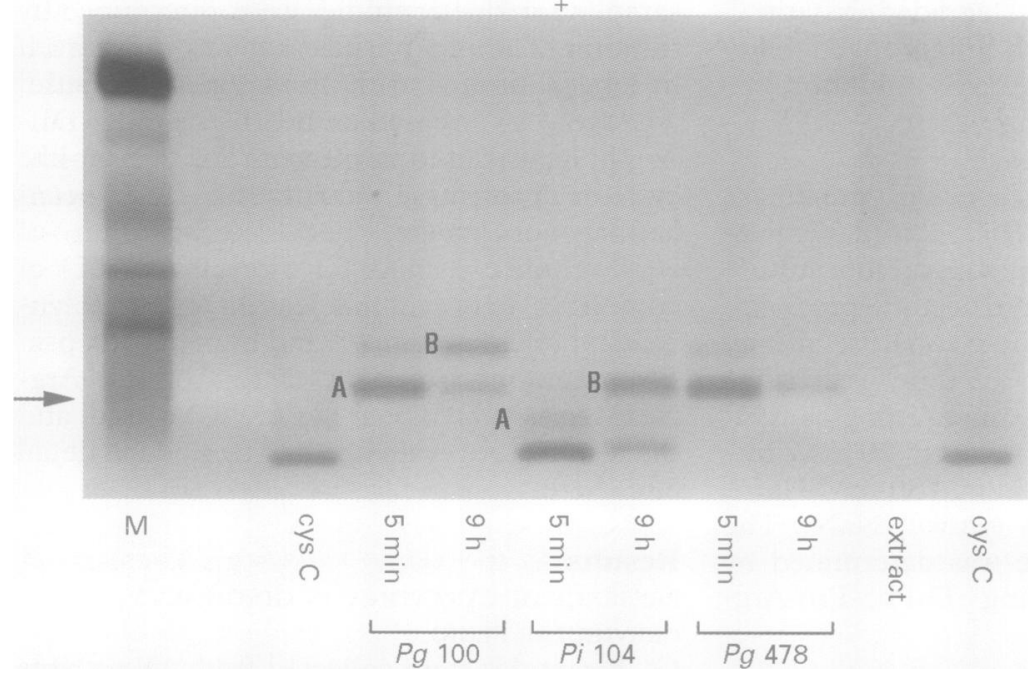

Figure 2 Time course experiments for the modification of cystatin $C$ by periodontopathic bacteria. Mixtures of cystatin $C$ and extracts of Porphyromonas gingivalis or Prevotella intermedia were incubated at $37^{\circ} \mathrm{C}$ in physiological buffer containing $10 \mathrm{mM}$ cysteine. Samples were taken from the mixtures after different periods of time and analysed by agarose gel electrophoresis. Three different cystatin $C$ cleavage patterns were apparent for the incubation mixtures, as exemplified by P gingivalis OMGS 100 (Pg 100; similar pattern as for OMGS 58, 590, 656); P gingivalis OMGS 478 (Pg 478; as OMGS 64, 588); P intermedia OMGS 104 (Pi 104; as OMGS 53, 105). The first modified cystatin $C$ bands (marked $A$ ) to appear, as well as those appearing on longer incubations (marked $B$ ), were subjected to $N$-terminal sequencing after blotting on to poly(vinyldifluoride) membranes (see fig 3). The anode and point of sample application are indicated by a plus sign and an arrow, respectively. $M$, human blood plasma, as reference; cys $C$, incubation mixture without bacterial extract; extract, incubation mixture without cystatin $C$. strate. To investigate whether $P$ gingivalis contained and secreted enzymes acting on cystatin $\mathrm{C}$ as a substrate, a screening assay with cultures of $P$ gingivalis grown on cystatin C coated Petri dishes was used. Cultures of the other two principal periodontitis pathogens, $P$ intermedia and $A$ actinomycetemcomintans, were also analysed. The results (fig 1 ) demonstrated clearly that both $P$ gingivalis and $P$ intermedia secreted cystatin C degrading enzymes, whereas $A$ actinomycetemcomintans did not.

To further characterise the bacterial interaction with cystatin C, extracts of five $P$ gingivalis and five $P$ intermedia strains were generated and used for incubations with cystatin $C$ in physiological buffer. Analysis by charge separating gel electrophoresis revealed three different patterns of limited cystatin $\mathrm{C}$ hydrolysis caused by the different strains (fig 2). Also, the rates of disappearance of the native cystatin $C$ in the incubation mixtures varied markedly, indicating varying amounts of cystatin degrading enzymes in the different strains. The hydrolysis products were characterised by $\mathrm{N}$-terminal sequencing (fig 3), demonstrating that the hydrolysis events causing altered electrophoretic mobility of cystatin $\mathrm{C}$ were all cleavages of bonds in the $\mathrm{N}$-terminal inhibitor segment. The predominant $P$ gingivalis cleavage was at the bond Arg8-Leu9, but an additional cleavage at the Val10-Gly11 bond was also observed for two of the strains analysed. The $P$ intermedia strains cleaved the Lys5-Pro6 and Pro7-Arg8 bonds predominantly, but on longer incubations the Leu9Val10 bond was also cleaved (fig 3).

To verify that $P$ gingivalis also releases cystatin $\mathrm{C}$ degrading activity, as indicated by the results from the culture screening assay, culture medium from the free growing strain $\mathrm{H} 66$ was incubated with cystatin C. Again, $\mathrm{N}$-terminal sequencing demonstrated that the medium contained enzyme activity that caused cleavage of $\mathrm{N}$-terminal segment cystatin $\mathrm{C}$ bonds. The predominant cleavage resulting from incubation with this medium was at the Arg8-Leu9 bond (fig 3).

Because the predominant cystatin $\mathrm{C}$ cleavage caused by $P$ gingivalis (at the Arg8-Leu9 bond) agrees with the substrate specificity of gingipain $\mathbf{R}$, an enzyme for which two molecular mass forms have been characterised recently in detail, ${ }^{24}{ }^{25}$ the low molecular mass enzyme of $50 \mathrm{kDa}$ was isolated from $P$ gingivalis strain H66. Incubation of the enzyme with cystatin $C$ at a $1: 100$ ratio revealed a rapid conversion (half life approximately two minutes) of the native cystatin $C$ to a modified form with lower molecular mass (fig 4). $\mathrm{N}$-terminal sequencing of the incubation mixture after five minutes incubation gave the single sequence Leu-Val-Gly-Gly-Pro-Met-, strongly indicating that gingipain $R$ is the enzyme responsible for the predominant cystatin $\mathrm{C}$ cleavage in the various $P$ gingivalis extracts and culture media. Probably this enzyme is also responsible for the inhibitor degrading activity observed in the assay of $P$ gingivalis secreted proteolytic enzymes. 


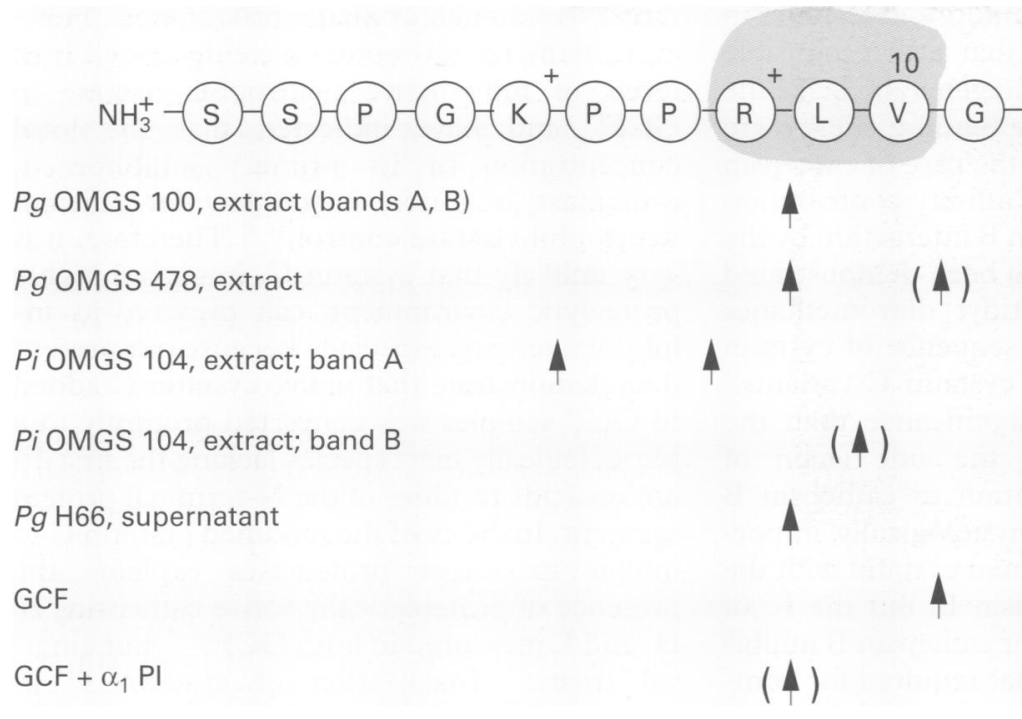

Figure 3 Points of cystatin $C$ hydrolysis caused by enzymes from periodontopathic bacteria. The $N$-terminal cystatin $C$ sequence is shown, with amino acid residues indicated by the standard one letter code. The residues with positively charged side chains are indicated, as are the residues known to participate directly in binding to the target enzyme, cathepsin $B$ (shaded area). The bonds being cleaved by the different bacterial strains in physiological buffer containing $10 \mathrm{mM}$ cysteine are marked with arrows, with parentheses indicating minor (less than 25\% of the major) cleavage points. Pi, Prevotella intermedia; $P g$, Porphyromonas gingivalis; GCF+a, PI, gingival crevicular fluid preincubated with $a_{1}$ proteinase inhibitor.

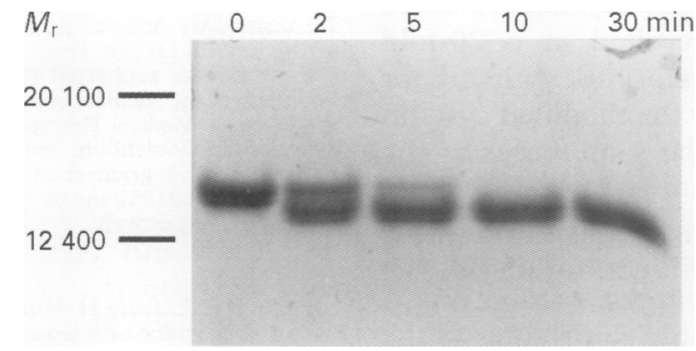

Figure 4 Time course experiment for the modification of cystatin $C$ by isolated $50 \mathrm{kDa}$ gingipain $R$. A mixture of cystatin $C$ and isolated gingipain $R$, at a molar ratio of $100: 1$, was incubated at $37^{\circ} \mathrm{C}$ and $\mathrm{pH}$ 7.4. Samples were taken after different periods of time and analysed by sodium dodecyl sulphate-polyacrylamide gel electrophoresis. The sizes of relevant molecular size markers are given on the left.

PROPERTIES OF P GINGIVALIS MODIFIED CYSTATIN C

An aliquot of $2 \mathrm{mg}$ cystatin $\mathrm{C}$ was incubated with $3 \mathrm{mg}$ of a lyophilised $P$ gingivalis OMGS 100 extract for three hours, after which no native cystatin $C$ could be detected by agarose gel electrophoresis of the sample. The initially formed modified cystatin C (band A in fig 2) was isolated to a purity of at least $95 \%$ as judged by electrophoresis. It had an approximate $M_{r}$ according to gel chromatography on Superose 12 of 13300 . Native cystatin C eluted from the same column at a volume corresponding to an $M_{r}$ of 13700 . SDS-PAGE with reducing or non-reducing conditions gave $M_{r}$ estimations for the modified and native cystatin C of 14500 and 15300 , respectively. $\mathrm{N}$-terminal sequencing and amino acid analysis were consistent with the modified cystatin C being devoid of the Ser1-Arg8 octapeptide.

The isolated modified cystatin $C$ was used for inhibition studies. It was $37 \%$ active as an inhibitor of papain under titrating conditions, compared with an activity. of $58 \%$ obtained for parallel analysis of native recombinant cystatin C. The equilibrium constants for dissociation
$\left(\mathrm{K}_{\mathrm{i}}\right)$ of the modified and native inhibitors from complexes with cathepsin B were determined to be $5.0 \mathrm{nM}$ and $0.27 \mathrm{nM}$, respectively; therefore, the modified inhibitor had a 20 -fold lower affinity for the proteinase.

\section{INTERACTION BETWEEN GCF COMPONENTS AND}

CYSTATIN C

To investigate the net effect of proteinases and their inhibitors in GCF on cystatin C, two GCF samples were supplemented with cystatin $\mathrm{C}$ at $0.5 \mathrm{mg} / \mathrm{ml}$ and incubated at $37^{\circ} \mathrm{C}$. The added cystatin $\mathrm{C}$ was converted rapidly to a form with altered electrophoretic mobility (with $t_{0.5}$ for the disappearance of native cystatin $\mathrm{C}$ of approximately two hours). $\mathrm{N}$-terminal sequencing of the modified gel band gave the single sequence Gly-Gly-Pro-Met-Asn- for both samples. The Val10-bond cleavage giving rise to this modified form of cystatin $\mathrm{C}$ is characteristic of neutrophil elastase, ${ }^{6}$ which is abundant in GCF. ${ }^{16}$ Neutrophil elastase cleavage of cystatin $C$ results in a 350-fold decreased cathepsin B affinity of cystatin C, rendering the inhibitor inactive at physiological concentrations. ${ }^{6}$

To verify that the GCF mediated cleavage of cystatin $\mathrm{C}$ was due to the activity of neutrophil elastase, and to investigate if additional cleavages of more $\mathrm{N}$-terminal cystatin $\mathrm{C}$ bonds by GCF components were masked by the Val10bond cleavage, GCF samples were preincubated with $\alpha_{1}$ proteinase inhibitor ( $1 \mathrm{mg} / \mathrm{ml}$ ). When the pretreated GCF was incubated with cystatin $C$, the rapid cystatin $C$ cleavage seen previously was absent. However, after prolonged incubation ( 24 hours at $37^{\circ} \mathrm{C}$ ), $30 \%$ of the added cystatin $\mathrm{C}$ displayed altered gel mobility. Sequencing of the modified cystatin $\mathrm{C}$ gave a unique $\mathrm{N}$-terminal sequence starting at residue Leu9 (fig 3), thus demonstrating that an additional cystatin C degrading enzyme with Arg-Xaa bond specificity was present in the GCF. It was probably gingipain $R$ because the Arg8-Leu9 peptide bond cleavage was not seen in a parallel incubation mixture in which the reducing agent ( $10 \mathrm{mM}$ cysteine) had been omitted and, therefore, the action of host Arg-Xaa specific serine proteinases could be ruled out. Supporting this, activity of gingipain $R$ has been detected in GCF and its activity has been correlated with the presence of $P$ gingivalis in subgingival plaques. ${ }^{42}$

\section{Discussion}

In the present investigation we have demonstrated that the periodontopathic bacteria, $P$ gingivalis and $P$ intermedia, contain and secrete cysteine proteinases that are not inhibited by the major human inhibitor of papain-like enzymes, cystatin C. Instead, the bacterial enzymes modify cystatin $\mathrm{C}$ by catalysing the cleavage of bonds in the $\mathrm{N}$-terminal inhibitor segment. This segment has been shown to constitute one discrete binding region invoved in the interaction with target enzymes like cathepsins $\mathrm{B}, \mathrm{H}, \mathrm{L}$, and $\mathrm{S} .{ }^{8}$ The remaining target proteinase binding area is built from two hairpin loops formed by the more C-terminal cystatin C segments Gln55-Gly59 and 
Pro 105-Trp106..$^{9}$ The amino acid residues in the $\mathrm{N}$-terminal segment that are responsible for the enzyme binding, and generally make the largest contribution to the binding energy, are Leu 9 and Val $10 .^{8}$ But in the case of cathepsin $\mathrm{B}$ inhibition, a significant affinity contribution to the cystatin C-cathepsin B interaction by the side chain of Arg8 has also been demonstrated by both studies of peptidyl diazomethanes based on the $\mathrm{N}$-terminal sequence of cystatin $\mathrm{C}^{43}$ and in vitro mutated cystatin $\mathrm{C}$ variants. ${ }^{8}$ Although of much less significance than the interaction mediated by the side chain of Val10, the Arg8 contribution to cathepsin B binding appears to be physiologically important. Cystatin $C$ is the human cystatin with the highest affinity for cathepsin $B$, but the $K_{i}$ of the wild-type cystatin $C$ for cathepsin $B$ inhibition is on the border of that required for complete inhibition by a reversible inhibitor in vivo. ${ }^{114}$ Hence, smaller contributions to the inhibitor affinity for this enzyme should also be deemed significant. The major cystatin C cleavage observed after interaction with $P$ gingivalis is at the bond Arg8-Leu9, thus, the $\mathrm{N}$-terminal octapeptide of the inhibitor including residue Arg8 is lost. Functional characterisation of the thereby modified cystatin revealed that the modification resulted in a 20 -fold decreased affinity for cathepsin $\mathrm{B}$, with a $\mathrm{K}_{\mathrm{i}}$ for cathepsin $B$ inhibition by the modified cystatin $C$ of $5 \mathrm{nM}$. This is of the same order as the cystatin $C$ concentration we measured in gingival crevicular fluid (15 $\mathrm{nM})$. Thus, the cystatin $C$ inhibition of cathepsin $B$ is impeded owing to the $P$ gingivalis interaction. As a result, cathepsin B probably contributes to the tissue destruction at the sites of inflammation in periodontitis.

The ability of $P$ gingivalis to cleave cystatin C was due predominantly to the presence of gingipain R; however, two of five tested strains exerted proteolytic activity also able to split the inhibitor after Val10. Such a cleavage has a more pathological significance because it renders cystatin $\mathrm{C}$ physiologically inactive against cathepsins $\mathrm{L}$ and $\mathrm{H}$ as well as cathepsin B. ${ }^{6}$ Also, this result indicates that in addition to gingipains $\mathrm{R}$ and $\mathrm{K}$ other proteolytic enzymes are also produced by $P$ gingivalis. Enzymes with substrate specificities corresponding to the additional cystatin $C$ cleavages observed have not yet been purified, although the presence of two genes encoding distinct candidate cysteine proteinases have been reported. ${ }^{45} 46$

It is known that $P$ intermedia is able to degrade immunoglobulins, ${ }^{47}$ fibronectin, ${ }^{48}$ and some other plasma proteins, ${ }^{49}$ but regarding the characterisation of its proteinases, $P$ intermedia still remains terra incognita. The main $P$ intermedia cystatin $\mathrm{C}$ cleavage sites reported here, although probably without affect on inhibitor activity, shed some light on the specificity of enzymes produced by this bacterium and might facilitate their future purification.

The presence of cystatin C in GCF has been determined using an immunochemical technique (this report) or by the inhibition of papain ${ }^{50}$; both methods detect cystatin C regardless of physiological ability to control its target lysosomal cysteine proteinases. However, many recent reports have described high levels of fully active neutrophil elastase in $\mathrm{GCF}^{16}$ and have indicated that the local concentration of its primary inhibitor, $\alpha_{1}$ 으 proteinase inhibitor, is too low for efficient 0 neutrophil elastase control. ${ }^{51}{ }^{52}$ Therefore, it is very unlikely that cystatin $\mathrm{C}$, in such a highly proteolytic environment, can preserve its inhibitory activity, especially because our present $\bar{c}$ data demonstrate that native cystatin $C$ added $\frac{\bar{\sigma}}{\bar{D}}$ to GCF samples was converted promptly to a $\frac{\widehat{D}}{\widehat{D}}$ physiologically inert species lacking the first $10 \stackrel{\varnothing}{\circ}$ amino acids residues of the $\mathrm{N}$-terminal protein segment. Inability of the modified cystatin $C$ to $\overrightarrow{0}$ inhibit its target proteinases explains the $\vec{\overrightarrow{ }}$ presence of proteolytically active cathepsins $\mathrm{B}, \stackrel{\omega}{\omega}$ $\mathrm{H}$, and $\mathrm{L}$ measured in both $\mathrm{GCF}^{1653}$ and gingival tissue. ${ }^{54}$ Inactivation of cystatin $C$ in periodontitis lesions might have a profound pathological consequence because it is well established that lysosomal cysteine proteinases are involved in bone resorption ${ }^{55}$ and that their 을 inhibitors suppress this process in several models, including isolated osteoclasts cultured on calcified surfaces. ${ }^{56}$

We thank Mrs Anne-Cathrine Löfström for skillful technical assistance and Dr Jim Travis for support and encouragement. This work was supported by grants from Magn. Bergvall's Foundation, the Medical Faculty of the University of Lund and . the Swedish Medical Research Council (Project No. 09915). The work in Gothenburg and at the University of Georgia was supported by a grant from the Swedish Medical Research Council (No. 09125) and by National Institutes of Health grant DE 09761, respectively.

1 Grubb A, Löfberg H. Human gamma-trace, a basic microprotein: amino acid sequence and presence in the adenohy- $O$ protein: amino acid sequence and presence in the aden

2 Abrahamson M, Grubb A, Olafsson I, Lundwall Å. Molecular cloning and sequence analysis of cDNA coding for the precursor of the human cysteine proteinase inhibitor cystatin C. FEBS Lett 1987;216:229-33.

3 Barrett AJ, Davies ME, Grubb A. The place of human $\gamma$-trace (cystatin C) amongst the cysteine proteinase inhibi- 0 tors. Biochem Biophys Res Commun 1984;120:631-6.

4 Brömme D, Rinne R, Kirschke H. Tight-binding inhibition of cathepsin S by cystatins. Biomed Biochim Acta 1991;50: of cath $631-5$.

5 Abrahamson M, Ritonja A, Brown MA, Grubb A, Machleidt W, Barrett AJ. Identification of the probable inhibitory reactive sites of the cysteine proteinase inhibitors human cystatin $C$ and chicken cystatin. $\mathcal{F}$ Biol Chem 1987; 262:9688-94.

6 Abrahamson M, Mason RW, Hansson H, Buttle DJ, Grubb A, Ohlsson K. Human cystatin C: role of the N-terminal $\sigma$ segment in the inhibition of human cysteine proteinases $\mathrm{N}$ and in its inactivation by leucocyte elastase. Biochem $\mathcal{F} \mathrm{O}$ and in its inactiva

7 Hall A, Dalbøge H, Grubb A, Abrahamson M. Importance $\omega$ of the evolutionarily conserved glycine residue in the $\mathrm{N}$-terminal region of cystatin C (Gly-11) for cysteine endopeptidase inhibition. Biochem f 1993;291:123-9.

8 Hall $\mathrm{A}$, Håkansson $\mathrm{K}$, Mason RW, Grubb A, Abrahamson $\mathscr{\varrho}$ M. Structural basis for the biological specificity of cystatin? C. Identification of leucine 9 in the $\mathrm{N}$-terminal binding region as a selectivity-conferring residue in the inhibition of mammalian

9 Bode W, Engh R, Musil D, Thiele U, Huber R, Karshikov A, et al. The $2.0 \AA$ X-ray crystal structure of chicken egg white cystatin and its possible mode of interaction with cysteine proteinases. EMBO F 1988;7:2593-9.

10 Ekiel I, Abrahamson M, Fulton DB, Lindahl P, Storer AC, 8 Levadoux W, et al. NMR structural studies of human cystatin C dimers and monomers. F Mol Biol 1997;271: 266-77.

11 Abrahamson M, Salvesen G, Barrett AJ, Grubb A. Isolation of six cysteine proteinase inhibitors from human urine. Their physicochemical and enzyme kinetic properties and concentrations in biological fluids. 7 Biol Chem 1986;261: 11282-9.

12 Assfalg-Machleidt I, Jochum M, Klaubert W, Inthorn D, Machleidt W. Enzymatically active cathepsin B dissociating from its inhibitor complexes is elevated in blood plasma of patients with septic shock and some malignant tumors. Biol Chem Hoppe-Seyler 1988;369(suppl):263-9. 
13 Köppel P, Baici A, Keist R, Matzku S, Keller R. Cathepsin B-like proteinase as a marker for metastatic tumor cell variants. Exp Cell Biol 1984;52:293-9.

14 Gabrijelcic D, Annan-Prah A, Rodic B, Rozman B, Cotic V, Turk V. Determination of cathepsins $B$ and $H$ in sera and synovial fluids of patients with different joint diseases. $\mathcal{f}$ Clin Chem Clin Biochem 1990;28:149-53.

15 Buttle DJ, Burnett D, Abrahamson M. Levels of neutrophil elastase and cathepsin B activities, and cystatins in human sputum: relationship to inflammation. Scand f Clin Lab Invest 1990;50:509-16.

16 Cox SW, Eley BM. Detection of cathepsin B- and L-, elastase-, tryptase-, trypsin-, and dipeptidyl peptidase IV-like activities in crevicular fluid from gingivitis and periIV-like activities in crevicular fluid from gingivitis and periodontitis patients with peptidyl derivatives of 7-amino-4-

17 Björck L, Åkesson P, Bohus M, Trojnar J, Abrahamson M, Olafsson I, et al. Bacterial growth inhibited by a synthetic inhibitor based upon the structure of a human proteinase inhibitor. Nature 1989;337:385-6.

18 Potempa J, Dubin A, Korzus G, Travis J. Degradation of elastin by a cysteine proteinase from Staphylococcus aureus. F Biol Chem 1988;263:2664-7.

19 Siffert O, Emöd I, Keil B. Interaction of clostripain with natural trypsin inhibitors and its affinity labeling by Na-pnitrobenzyloxycarbonyl arginine chlormethyl ketone. FEBS Lett 1976;66:114-19.

20 Slots J, Bragd L, Wikström M, Dahlén G. The occurrence of Actinobacillus actinomycetemcomitans, Bacteroides gingivalis and Bacteroides intermedius in destructive periodontal disease in adults. $\mathcal{F}$ Clin Periodontol 1986;13:570-7.

21 Travis J, Pike R, Imamura T, Potempa J. Porphyromonas gingivalis proteinases as virulence factors in the development of periodontitis. $¥$ Periodontal Res 1997;32:120-5.

22 Birkedal-Hansen $H$, Taylor RE, Zambon JJ, Barw PK, Neiders ME. Characterization of collagenolytic activity from strains of Bacteroides gingivalis. $\mathcal{F}$ Periodont Res 1988 ; from strains

23 Hinode D, Nagata A, Ichimiya, S, Hayashi H, Morioka $M$, Nakamura R. Generation of plasma kinin by three types of protease generated from Porphyromonas gingivalis 381 . Arch Oral Biol 1992;37:859-61.

24 Chen Z, Potempa J, Polanowski A, Wikström M, Travis J. Purification and characterization of a $50-\mathrm{kDa}$ cysteine proteinase (gingipain) from Porphyromonas gingivalis. $\mathcal{f} \mathrm{Biol}$ Chem 1992;267:18896-901.

25 Pike R, McGraw W, Potempa J, Travis J. Lysine- and arginine-specific proteinases from Porphyromonas gingivalis. Isolation, characterization, and evidence for the existence of complexes with hemagglutinins. F Biol Chem 1994;269:406-11.

26 Pavloff N, Potempa J, Pike RN, Prochazka V, Kiefer MC Travis $\mathrm{J}$, et al. Molecular cloning and characterization of Porphyromonas gingivalis lysine-specific gingipain. A new member of an emerging family of pathogenic bacterial cysteine proteinases. F Biol Chem 1995;270:1007-10.

27 Potempa J, Pike R, Travis J. The multiple forms of trypsinlike activity present in various strains of Porphyromonas gingivalis are due to the presence of either Arg-gingipain or Lys-gingipain. Infect Immun 1995;63:1176-82.

28 Abrahamson M, Dalbøge H, Olafsson I, Carlsen S, Grubb A. Efficient production of native, biologically active human cystatin C by Escherichia coli. FEBS Lett 1988;236:14-8.

29 Rich DH, Brown MA, Barrett AJ. Purification of cathepsin B by a new form of affinity chromatography. Biochem $\mathcal{F}$ 1986;235:731-4

30 Blumberg A, Schechter I, Berger A. The purification of papain by affinity chromatography. Eur $\mathcal{F}$ Biochem 1970;15: 97-102.

31 Jeppsson J-O, Laurell C-B, Franzén B. Agarose gel electrophoresis. Clin Chem 1979;25:629-38.

32 Laemmli UK. Cleavage of structural proteins during the assembly of the head of bacteriophage T4. Nature 1970;227:680-5.

33 Matsudaira P. Sequence from picomole quantities of proteins electroblotted onto polyvinylidene difluoride membranes. ₹ Biol Chem 1987;262:10035-8.

34 Olafsson I, Gudmundsson $\mathrm{G}$, Abrahamson $\mathrm{M}$, Jensson $\mathrm{O}$ Grubb A. The aminoterminal portion of cerebrospinal fluid cystatin $C$ in hereditary cystatin $C$ amyloid angiopathy is not truncated. Direct sequence analysis from agarose gel electropherograms. Scand $\mathcal{F}$ Clin Lab Invest 1990;50:8593.
35 Lindahl P, Abrahamson M, Björk I. Interaction of recombinant human cystatin $\mathrm{C}$ with the cysteine proteinases papain and actinidin. Biochem F 1992;281:49-55.

36 Renvert S, Wikström M, Dahlén G, Slots J, Egelberg J. On the inability of root debridement and periodontal surgery to eliminate Actinobacillus actinomycetemcomitans from periodontal pockets. $\mathcal{F}$ Clin Periodontol 1990;17:351-5.

37 Olafsson I, Löfberg $\mathrm{H}$, Abrahamson $\mathrm{M}$, Grubb A Production, characterization and use of monoclonal antibodies against the major extracellular human cysteine proteinase inhibitors cystatin $\mathrm{C}$ and kininogen. Scand $\mathcal{f}$ proteinase inhibitors cystatin Cab Invest 1988;48:573-82.

38 Wikström MB. Detection of microbial proteolytic activity by a cultivation plate assay in which different proteins adsorbed to a hydrophobic surface are used as substrates. Appl Environ Microbiol 1983;45:393-400.

39 Johansson BG. Agarose gel electrophoresis. Scand 7 Clin Lab Invest 1972;29(suppl 124):7-19.

40 Barrett AJ, Kembhavi AA, Brown MA, Kirschke H, Knight $\mathrm{CG}$, Tamai $\mathrm{M}$, et al. L-trans-epoxysuccinyl-leucylamido(4guanidino)butane (E-64) and its analogues as inhibitors of cysteine proteinases including cathepsins $\mathrm{B}, \mathrm{H}$ and $\mathrm{L}$. Biochem f 1982;201:189-98.

41 Abrahamson M. Cystatins. Methods Enzymol 1994;244:685700 .

42 Wikström M, Potempa J, Polanowski A, Travis J, Renvert S Detection of Porphyromonas gingivalis in gingival exudate by a dipeptide-enhanced trypsin-like activity. 7 Periodontol 1994;65:47-55.

43 Hall A, Abrahamson M, Grubb A, Trojnar J, Kania P, Kasprzykowska $\mathrm{R}$, et al. Cystatin $\mathrm{C}$ based peptidyl
diazomethanes as cysteine proteinase inhibitors: Influence diazomethanes as cysteine proteinase inhibitors: Influence 23.

44 Bieth JG. Pathophysiological interpretation of kinetic constants of protease inhibitors. Bull Eur Physiopath Resp 1980;16(suppl): 183-95.

45 Bourgeau G, Lapointe H, Peloquin P, Mayrand D. Cloning, expression, and sequencing of a protease gene (tpr) from Porphyromonas gingivalis W83 in Escherichia coli. Infect Immun 1992;60:3186-92.

46 Madden TE, Clark VL, Kuramitsu HK. Revised sequence of the Porphyromonas gingivalis prtT cysteine protease/ hemagglutinin gene: homology with streptococcal pyrogenic exotoxin $\mathrm{B} /$ streptococcal proteinase. Infect Immun 1995;63:238-47.

47 Kilian M. Degradation of immunoglobulins A2, A2, and G by suspected principal periodontal pathogens. Infect Immun 1981;34:757-65

48 Wikström M, Linde A. Ability of oral bacteria to degrade fibronectin. Infect Immun 1986;51:707-11.

49 Carlsson J, Höfling JF, Sundqvist GK. Degradation of albumin, haemopexin, haptoglobin and transferrin, by blackpigmented Bacteroides species. F Med Microbiol 1984;18: pigmen $39-46$.

50 Ichimaru E, Imura K, Hara Y, Kato I. Cystatin activity in gingival crevicular fluid from periodontal disease patients measured by a new quantitative analysis method. $\mathcal{f}$ Periodont Res 1992;27:119-25.

51 Ohlsson K, Olsson I, Tynelius-Bratthall G. Neutrophil leukocyte collagenase, elastase and serum protease inhibitors in human gingival crevicles. Acta Odontol Scand 1974;31: $51-9$

52 Smith QT, Wang, Y, Sim B. Inhibition of crevicular fluid neutrophil elastase by $\alpha_{1}$-antitrypsin in periodontal health and disease. Arch Oral Biol 1994;39:301-6.

53 Lah T, Skaleric U, Babnik J, Turk V. Detection of cathepsin L-like proteinase and cathepsin D in gingival fluid. $f$ Periodont Res 1986;21:504-9.

54 Kennett CN, Cox SW, Eley BM. Comparative histochemi$\mathrm{cal}$, biochemical and immunocytochemical studies of cathepsin B in human gingiva. $\mathcal{F}$ Perodont Res 1994;29:20313.

55 Delaissé J-M, Eeckout Y, Vaes G. In vivo and in vitro evidence for the involvement of cysteine proteinases in bone resorption. Biochem Biophys Res Commun 1984;125: 441-7.

56 Rifkin BR, Vernillo A, Kleckner AP, Auszmann J, Rosenberg $\mathrm{L}$, Zimmerman $\mathrm{M}$. Cathepsin B and $\mathrm{L}$ activities in isolated osteoclasts. Biochem Biophys Res Commun 1991;179:63-9. 